\title{
To cognition of the scientific contribution of Professor L.I. Malyshev to the floristic research of Siberia and other territories: a brief analytical review
}

\author{
Vladimir Doronkin", Natalia Vlasova, and Konstantin Baikov \\ Central Siberian Botanical Garden SB RAS, 630090 Novosibirsk, Russia
}

\begin{abstract}
Analytical review of scientific contribution of Professor Malyshev is performed and presented on the floristic research of Siberia and other territories (Ural Mountains, Mongolia, Russian Far East, etc.). It was shown, that there were several stages in these researches: from Eastern Sayan to Stanovoy Uplands, Putorana Plateau, and then Central (Baikalian Siberia and Dahuria) Siberia, Siberia in whole, and joined flora of Siberia and Russian Far East, usung different methodical approaches (method of concrete flora of A.I. Tolmachev adopted to mountain regions, and various techniques of multivariate statistics, such as rank correlations for familiesspecies, families-genera, and genera-species in head parts of taxonomic spectra, usually consists of 10 to 20 taxa (families or genera). To solve some florogenetic issues, the concept of floristic complexes as stable groups of species located in a certain belt of mountains (for example, alpine and mountain-steppe) was proposed and applied. At all stages of floristic research, the task was set to maximally identify the species composition on territories of various sizes for subsequent subdivision, with the identification of the boundaries for floristic regions, subregions, provinces and sub-provinces. The local floras and working floristic districts were taken as the basic elements of such division.
\end{abstract}

\section{Introduction}

The cognition of the contribution of scientific leaders is extremely important for father development in any direction of research, insofar as the original way of an approximation to the true knowledge. In this aspect, the understanding of scientific inputs of Professor Leonid Ivanovich Malyshev (1931-2014) has of great importance in the progress of floristic and taxonomical researches, especially of vascular plants in Siberia and adjacent territories.

Below we will consider the most significant concepts and methodological solutions that allowed L.I. Malyshev to carry out unique studies of the high-mountain flora of the Eastern Sajan, Stanovoy Upland, and the Putorana plateau [1-3].

\footnotetext{
*Corresponding author: norbo@ngs.ru
} 
The purpose of this study was a comparative analysis of materials and methods, as well as the most significant publications of L.I. Malyshev, to highlight the main scientific results. To achieve this purpose, we need to solve a number of specific tasks, including: determine the suitability of the quantitative methods used in these publications as an effective tool for generating new knowledge; to establish the prospects for the simultaneous use of several methods of analysis; to assess the applicability of quantitative methods for solving taxonomic insights within polymorphic boreal genera.

\section{Material and methods}

L.I. Malyshev began studying the flora of East Sayan Mountains in 1957. The research program was planned for 6 years. The alpine flora of the Tunkinsky Range was surveyed in the summer of 1957. Materials on the alpine flora of the Kitoysky Range were collected in 1958. Botanical studies of the highlands of the Pogranichny Range and the Munku-Sardyk mountain range were carried out in 1959. Floristic studies of the Belsky Uplands, the Okinsky and Udinsky Ranges, the Dzhidinsky Highlands and the Agul Range were carried out in the period from 1960 to 1962. As a result, the alpine floras of all main ranges of East Sayan Mountains was studied, except the far western part located within Krasnoyarsk region [1]. The herbarium materials (over 10000 sheets) were collected mainly in highlands.

From 1963 to 1968 detailed forwarding researches of Stanovoy Highlands mountain flora were carried out. The concrete floras method proposed by A.I. Tolmachev [4] as well as a route method were applied. From 5 to 15 points, altogether 74 points, were inspected on each ridge. Visiting hard-to-reach points were carried out by means of the helicopter. Many points were inspected for the first time. Eight new species of plants were found, 52 rare species were collected (some were revealed for the first time). The species list, the characteristic of flora, the distribution map of types are given in the collective monograph "Mountain flora of Stanovoy Highland". The section on the analysis of genesis and features of the flora was carried out by L.I. Malyshev using mathematical methods of comparative floristics [2].

Systematic studying of Eastern Siberia flora gave the chance to start a research of specific structure of a most interesting region of a hypoarctic belt of Asia - the Putorana Plateau. The field works were performed in the period from 1968 to 1972. The seaplane was used for carrying out forwarding researches. L.I. Malyshev (research supervisor), N.S. Vodopyanova, M.M. Ivanova, Yu.N. Petrochenko, R.E. Krogulevich, S.Yu. Andrulaytis, L.V. Bardunov, A.A. Kiselyova, Z.D. Malysheva and the others took part in the trips, and A.I. Tolmachev as the scientific consultant. Fourteen geographical points were inspected by the concrete floras method and 10 more points by a route method. The received results are generalized in the scientific collection "Flora Putorana" [3]. The original approaches of the statistical analysis of flora and the ecological-geographical analysis were stated in the publication. Besides, earlier offered methods of floristic researches were applied [5].

The two-volume collective summary "Flora of Central Siberia" [6], covering the Buryat Autonomous Soviet Socialist Republic, Irkutsk and Chita regions, was prepared and published under his leadership and with his participation. The multivolume "Flora of Siberia" (2003-2007) includes 14 volumes, 10 volumes were published under edition of L.I. Malyshev and others [7]. Over 4500 species and subspecies are given in it. With the use of these materials researches on floristic zoning of Asian Russia into districts were carried out.

Many prospective methods of comparative floristics were developed and applied in the publications of L.I. Malyshev such as calculating the similarity coefficients for local floras, cluster analysis of complete species lists in the generating of schemes of floristic subdivision, and some other important approaches. 


\section{Results}

To illustrate the methods and approaches proposed and applied by L.I. Malyshev for a quantitative analysis of regional floras, we performed an analysis of the scientific results of the study of the flora of the Putorana Plateau (Northern Siberia) [8]. In this study, quantitative methods of comparative floristry are supplemented by an analysis of the chorological groups of species identified using computer modeling. One of the most significant results was the dendrogram of the similarity of 16 local floras generated by the share of 27 chorological groups of species in them. We excluded from consideration the local flora in the vicinity of Norilsk, which stands out among the other local floras of the Putorana Plateau both by a higher level of study and by its location outside the western boundary of this Plateau. The grouping of local floras is shown in Figure 1.

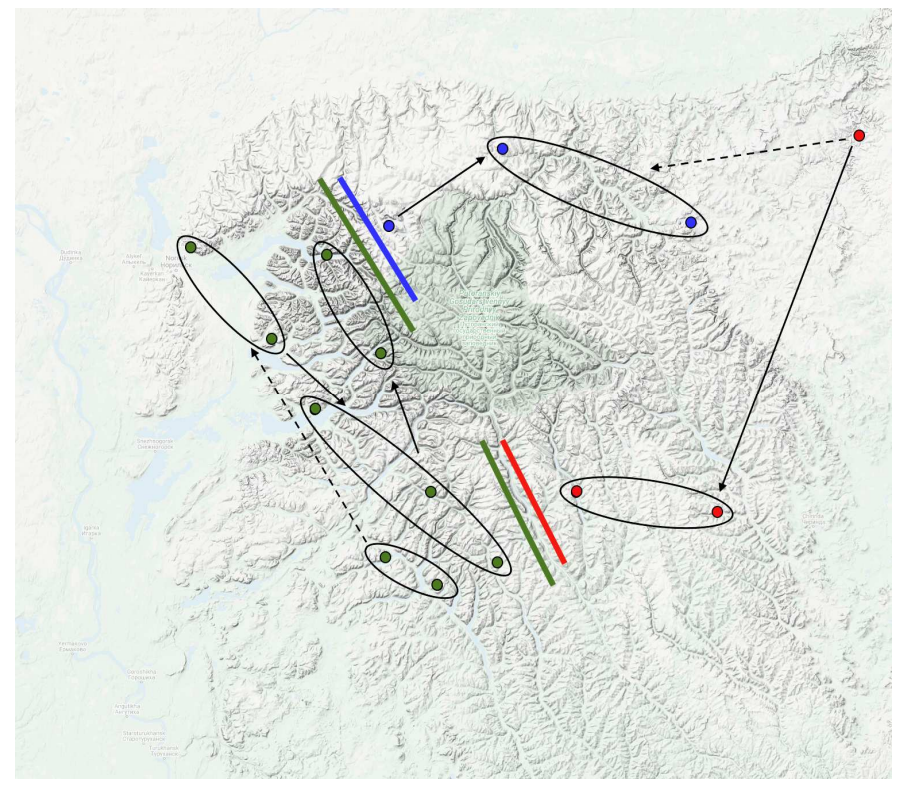

Fig. 1. Grouping of local floras of the Putorana plateau based on the dendrogram of the similarity [8]. Local floras of Western Putorana and their eastern border are marked in green, Northern Putorana - in blue, and Eastern Putorana - in red. Elliptical contours combine the most similar local flora. Arrows indicate grouping into high-order clusters. Solid lines indicate dividing lines between groups. The names of local floras and their coordinates are given in Table 1.

The most similar local floras are united by ellipses, between which arrows are drawn, connecting them into groups of higher orders. According to the results obtained [8, fig. 71], with the values of the correlation coefficient for the proportion of chorological groups of species equal to 0.27 and lower, the western group of local floras is reliably separated from the northern and eastern groups (see Figure 1). The dividing lines of these groups are shown with solid lines. Within the western group, the local floras of Imangda and Talnakh are most similar, in the northern group - Baselak and Bokovoye, in the eastern group Beldunchana and Khakoma.

Among 27 chorological clusters, we have selected seven subclusters, the share of which in the composition of local floras has the most contrasting values at the level of three distinguished groups of local floras: western, northern, and eastern. As part of the circumboreal chorological cluster, subcluster A1 was selected, including 44 species (Allium schoenoprasum, Andromeda polifolia, Baeothryon alpinum, etc.). The proportion of species of this subcluster does not exceed $30.0 \%$ in the local floras of the Northern group, varies 
from 36.8 to $45.6 \%$ in the eastern group and exceeds $50.0 \%$ in the Western group (Table 1). As part of the Eurasian chorological cluster, the B2 subcluster was selected, which includes 30 species (Alopecurus pratensis, Antennaria dioica, Artemisia vulgaris, etc.). The share of species participation in this subcluster varies from 6.9 to $24.1 \%$ in the local floras of the Northern and Eastern groups, and in the Western group it exceeds $41.4 \%$ (see Table 1).

Table 1. Calculated values for seven chorologic groups of vascular plants, accepted L.I. Malyshev et al. [8] to local floras within Putorana Plateau (N Siberia)

\begin{tabular}{|c|c|l|c|c|c|c|c|c|c|c|}
\hline 1 & \multicolumn{1}{|c|}{2} & \multicolumn{1}{|c|}{3} & 5 & 6 & 7 & 8 & 9 & 10 & 11 \\
\hline 088.40 & 69.50 & Talnakh & 66.7 & 48.3 & 76.9 & 73.3 & 19.0 & - & 57.1 & WP \\
\hline 089.70 & 69.10 & Imangda & 61.4 & 44.8 & 69.2 & 67.0 & 15.4 & - & 57.1 & WP \\
\hline 090.80 & 68.40 & Khantayskoe & 61.4 & 51.7 & 76.9 & 60.0 & 19.0 & 30.0 & 50.0 & WP \\
\hline 090.90 & 69.50 & Kapchuk & 71.9 & 55.2 & 76.9 & 67.0 & 19.0 & 30.0 & 64.3 & WP \\
\hline 091.70 & 67.60 & Ende & 54.4 & 41.4 & 61.5 & 60.0 & 23.1 & 10.0 & 50.0 & WP \\
\hline 092.00 & 68.80 & Kutaramakan & 54.4 & 41.4 & 76.9 & 60.0 & 15.4 & 30.0 & 57.1 & WP \\
\hline 092.00 & 67.30 & Severnoye & 50.8 & 51.7 & 61.5 & 73.3 & 7.7 & 10.0 & 42.9 & WP \\
\hline 092.40 & 69.70 & Bogatyr & 5.3 & 10.3 & 23.1 & 6.7 & 38.5 & 50.0 & 71.4 & NP \\
\hline 093.60 & 67.00 & Niakshingda & 61.4 & 51.7 & 76.9 & 60.0 & 15.4 & 30.0 & 35.7 & WP \\
\hline 094.10 & 67.20 & Tembenchy & 57.9 & 41.4 & 69.2 & 53.3 & 19.0 & 30.0 & 57.1 & WP \\
\hline 094.30 & 70.20 & Bokovoye & 29.8 & 6.9 & 53.8 & 26.7 & 46.2 & 70.0 & 78.6 & NP \\
\hline 095.80 & 67.80 & Beldunchana & 45.6 & 24.1 & 53.8 & 40.0 & 15.4 & 40.0 & 64.3 & EP \\
\hline 097.90 & 67.90 & Khakoma & 36.8 & 10.3 & 38.5 & 40.0 & 15.4 & 50.0 & 71.4 & EP \\
\hline 098.00 & 69.70 & Baselak & 26.3 & 17.2 & 46.2 & 26.7 & 46.2 & 50.0 & 71.4 & NP \\
\hline 101.20 & 70.20 & Khaya-Kuel & 36.8 & 17.2 & 38.5 & 26.7 & 38.5 & 40.0 & 42.9 & EP \\
\hline
\end{tabular}

Columns are: 1 - X (longitude), 2 - Y (latitude), 3 - Location names, 4 - Circumboreal (the subcluster A1 only; here and further labels for subclusters are given as in [8]), 5 - Eurasiatic (B2 only), 6 - Northeastern Siberian (C4 only), 7 - Central Siberian (D3 only), 8 - Arctic Siberian (E1 only), 9 - Circumarctic (F1 only), 10 - Amphi-Beringian (G2 only), 11 - expert estimation for floristic division (WP - Western Putorana, NP - Northern Putorana, EP - Eastern Putorana).

As part of the Northeastern Siberian chorological cluster, we selected the C4 subcluster, which includes 13 species and subspecies (Campanula rotundifolia subsp. langsdorffiana, Carex appendiculata, Deschampsia sukatschewii, etc.). The proportion of species participation in this subcluster varies from 23.1 to $53.8 \%$ in the local floras of the Northern and Eastern groups, and in the Western group exceeds 61.5\% (see Table 1). As part of the Central Siberian chorological cluster, we selected the D3 subcluster, which includes 15 species (Achillea impatiens, Aconitum baicalense, Androsace lactiflora, etc.). The proportion of species of this subcluster varies from 6.7 to $26.7 \%$ in the local floras of the Northern group, from 26.7 to $40.0 \%$ in the Eastern group, and more than $53.3 \%$ in the Western group. As part of the Arctic Siberian chorological cluster, the E1 subcluster was 
selected, which includes 13 species (Androsace triflora, Deschampsia obensis, Draba glacialis, etc.). The proportion of species of this subcluster is the highest in the local floras of the Northern group - more than $38.5 \%$; in the Eastern group it varies from 15.4 to $38.5 \%$, in the Western group it does not exceed 19.0\%. As part of the Circumarctic chorological cluster, we selected the F1 subcluster, which includes 10 species (Braya purpurascens, Cerastium regelii, Deschampsia borealis, etc.). The proportion of species of this subcluster is the highest in the local floras of the Northern group - 50.0-70.0\%, in the Eastern group it varies from 40.0 to $50.0 \%$, in the Western group it does not exceed $30.0 \%$ (see Table 1). The G2 subcluster was selected as part of the Amphi-Beringian chorological cluster, which includes 14 species (Luzula tundricola, Minuartia arctica, Minuartia macrocarpa, etc.). The share of species participation in this subcluster is the highest in the local floras of the Northern group - it exceeds $71.4 \%$ and is below this threshold value in the Eastern and Western groups. The above differences, not only quantitatively, but also qualitatively, in the form of non-overlapping intervals of variation, confirm the validity of the grouping of local floras of the Putorana Plateau into three clusters of the upper level. Moreover, the cluster, which includes nine local floras of the Western part of Putorana, is the most isolated from the other two.

Using and developing quantitative methods of comparative floristics allowed L.I. Malyshev to receive a number of important results on questions of a florogenesis of Southern Siberia mountains. Thus, it was so established that the highlands of Southern Siberia and adjacent Mongolia represent an independent center of the alpine speciation in Asia. Highlands of the Baikalian Siberia have a special value since they contain a set of endemic and hemiendemic species and subspecies. The connection in the group of mountain plants with mountains of Central Asia and the western perifery of Central Asia and also with mountains of East Asia is traced which indicates the value of Southern Siberia mountains for plants migrations, a so-called "Great trans-Asiatic mountain way" [9].

Application of new methodical approaches gave a chance to conduct a large-scale research on assessment of the USSR floristic richness [10]. It was revealed, for example, that in Western Siberia to the North from 60 latitude the depletion of flora appears, in comparison with similar areas in Eastern Europe and Eastern Siberia.

The family-species and family-genus structure of 28 provisional floristic districts of Siberia, basing on the manual "Flora of Siberia" have been investigated. In the cluster analysis the Ward's method was adopted. The dendrograms of taxonomic structure are promising in the modeling of hierarchical floristic subdivisions. Accordingly, the familygenus spectra reveal more ancient trends in the floristic evolution, than the family-species and, especially, genus-species spectra [11].

Studying of taxonomical objects - genera, sections etc. has a certain model value for solving questions of a florogenesis and zoning. In the flora of Asian Russia the second place by number of species is occupied by the genus Oxytropis DC. (Fabaceae). One hundred and forty-two species and 24 subspecies as a part of 5 subgenera and 16 sections were revealed. Phenetics and chorology of the section Orobia Bunge (64 species) have been studied, and it has been established, that 31 species are endemics for the mountain regions of the southern part of Siberia. Altai-Yeniseian and Baikalian floristic provinces are the richest of the Oxytropis species, whereas lowland provinces of Western Siberia are the poorest of it [12]. On the initiative of L.I. Malyshev the research on distribution of the species of the Arctobia Bunge section concentrated on the northeast of Asia and the northwest of North America (Area of Beringia) was conducted. The section includes 19 species and subspecies. For carrying out the phytogeographical analysis the means of GIS MapInfo Professional were used, and geostatistical methods were applied. The given section represents an ancient cryophile "branch" of the genus Oxytropis [13]. 
Throughout long-term researches of the Siberian flora Leonid Ivanovich Malyshev described 29 taxa as a new for science. Eleven new species of plants were named in his honor.

\section{Discussion}

Based on our analysis of some of the most significant methodological publications of L.I. Malyshev, the following conclusions can be formulated. The quantitative methods used in these publications are effective research techniques for generating new knowledge. The most significant results were obtained with the simultaneous use of several methods, such as identifying the species composition for the territory by the method of local floras, calculating the similarity coefficients for local floras, quantitative analysis of altitudinal groups for mountainous territories, the share of chorological groups in the composition of species in local floras, cluster analysis of complete species lists, and also the composition of the genera. To solve taxonomic issues in relation to polymorphic boreal genera, a quantitative method is proposed for assessing stable complexes of diagnostic characters and the correspondence of its results to chorological data, using the example of the genus Oxytropis. At the stage of comparison of the results obtained, the consensus of expert opinions and its complementarity to the existing concepts of florogenetic processes are of particular importance.

This investigation was performed within the framework of the State assignment of the CSBG SB RAS, № AAAA-A21-121011290024-5. In preparing the publication, the scientific collection and bioresources database of Central Siberian Botanical Garden, Siberian Branch of Russian Academy of Science «Herbarium of vascular plants, lichens and fungi (NS, NSK)» USU 440537 were used.

\section{References}

1. L. I. Malyshev, Flora Alpina Montium Sajanensium Orientalium (Moscow-Leningrad, Nauka, 1965)

2. L. I. Malyshev (ed.), Alpine Flora of Stanovoy Uplands (Novosibirsk, Nauka, 1972)

3. L. I. Malyshev (ed.), Flora Putorana (Novosibirsk, Nauka, 1976)

4. A. I. Tolmachev, Journ. Russ. Bot. Soc., 16, 1 (1931)

5. L. I. Malyshev, Bot. J., 57 (1972)

6. L. I. Malyshev, G. A. Peschkova (ed.), Flora Sibiriae Centralis (Nauka, Novosibirsk, 1979)

7. Flora of Siberia (Science Publishers, Inc., Enfield of NH, USA - Plymouth, UK, 20032008)

8. P. L. Nimis, L. I. Malyshev, G. Bolognini, and N. Friesen, Opera Botanica, 136 (1998)

9. L. I. Malyshev, G. A. Peschkova, Features and genesis of the flora of Siberia (Cisbaikalia and Transbaikalia) (Nauka, Novosibirsk, 1984)

10. L. I. Malyshev, Floristic wealth of the USSR (Actual problems of comparative study of floras, St. Petersburg, 1994)

11. L. I. Malyshev, K. S. Baikov, V. M. Doronkin, Bot. J. 83, 10 (1998)

12. L. I. Malyshev, The flora of Asian Russia, 1 (2008)

13. N. V. Vlasova, E. I. Duchina, L. K. Trubina, The flora of Asian Russia, 1 (2008) 